\title{
Occurrence and fate of volatile siloxanes in a municipal Wastewater Treatment Plant of Beijing, China
}

\author{
Lin $\mathrm{Xu}$, Yali Shi, Yaqi Cai*
}

State Key Laboratory of Environmental Chemistry and Ecotoxicology, Research Center for Eco-Environmental Sciences, Chinese Academy of Sciences, Shuangqing Road 18\#, Haidian District, Beijing 100085, China

\section{A R T I C L E I N F O}

Article history:

Received 23 June 2012

Received in revised form

22 October 2012

Accepted 27 October 2012

Available online 12 November 2012

\section{Keywords:}

Volatile siloxanes

SPME/GC-MS

WWTP

Volatilization

Biodegradation

Adsorption

\begin{abstract}
A B S T R A C T
The occurrence and fate of four cyclic and two linear volatile siloxanes were studied in a municipal Wastewater Treatment Plant (WWTP), Beijing City, China. Aqueous and sludge samples were analyzed by solid-phase microextraction (SPME) coupled with gas chromatography-mass spectrometry (GC-MS). In the studied WWTP, four cyclic analogs (D3-D6) had significantly higher concentrations and frequencies than the two linear analogs [Octamethyltrisiloxane (L3) and Decamethyltetrasiloxane (L4)], with inputs into the WWTP ranging from 78.2 to $387.7 \mathrm{~kg} /$ year. Removal efficiencies of volatile cyclic siloxanes in two parallel secondary treatment processes ranged from 59.3 to $92.7 \%$. For volatile cyclic siloxanes, relative fractions of mass loss by adsorption to sludge ranged from 8.3 to $53.0 \%$, and their adsorption capacities were significantly affected by the dissolved organic matter. Besides adsorption, they were eliminated mainly in anaerobic units (44.4-84.3\%). Through in vitro biodegradation experiments, we concluded that in the anaerobic compartments, Hexamethylcyclotrisiloxane (D3) and Dodecamethylcyclohexasiloxane (D6) were eliminated mostly by volatilization, while Octamethylcyclotetrasiloxane (D4) and Decamethylcyclopentasiloxane (D5) may be eliminated by both volatilization and degradation. Furthermore, microbe catalysis hydrolysis was identified as one of the main degradation pathways for D4 and D5 in anaerobic compartments.
\end{abstract}

(c) 2012 Elsevier Ltd. All rights reserved.

\section{Introduction}

Siloxanes, a subgroup of silicones, consist of $\mathrm{Si}-\mathrm{O}$ bonds with aliphatic chains (mostly methyl groups) attached to Si atoms. Due to their low surface tension, high thermal stability and lubricating properties, siloxanes have been widely used for decades in industrial processes and consumer products such as cosmetics and health care products (SEHSC, 2011; Kannan, 2008). It was reported that the annual import/production volumes in the USA were 45-226 million kilograms for Octamethylcyclotetrasiloxane (D4) or Decamethylcyclopentasil oxane (D5) and 4.5-22.6 million kilograms for Dodecamethyl- cyclohexasiloxane (D6) (EPA, 2002). China is leading the world in cyclic siloxane production capacity, with an annual production of about 800 million kilograms (CNKI, 2009). Because the siloxane are produced in large quantities and used ubiquitously in consumer products, it is likely that they will enter into the environment. Because of their stability, siloxane residues may be persistent in the environment, and have the potential to bioaccumulate in organisms (Flassbeck et al., 2001; Kala et al., 1997). There have been studies reporting direct or indirect toxic effects of volatile siloxanes on both aquatic and terrestrial life. In an in vitro study, exposure to D4 via injection in mice caused fatal liver and lunge damage

\footnotetext{
* Corresponding author. Tel.: +86 (10) 62849182; fax: +86 (10) 62849182.

E-mail address: caiyaqi@rcees.ac.cn (Y. Cai). 
(Liebierman et al., 1999). Other reports indicated that oral exposure to D4 caused estrogenic effects on rats, and inhalation of D5 caused adverse effects on the nervous system of rats (He et al., 2003; OEHHA, 2007). Also, the European Union suggested that D4 interfered with human hormone function and might impair human fertility (EC, 2009).

One of the most significant pollution sources of volatile siloxanes is the emission from cosmetics, personal care and household products used by the general public. Approximately, $10 \%$ of them enter into domestic wastewater (EA, 2009a,b,c). The first step of removing volatile siloxane residues from domestic wastewater takes place at the WWTPs. It is therefore important to characterize the occurrence and fate of volatile siloxanes during the wastewater treatment processes. However, systematic investigations of their migration and removal mechanism are scarce. In one study, the removal behavior of D4 and D5 was analyzed by continuously dosing the influent with exaggerated amounts of these two compounds in a pilot-scale plant (Parker et al., 1999). However, because dosed compounds in the influent were inhomogeneous and did not reach equilibrium between the aqueous and solid phases, the mass balances of D4 and D5 were poor. In another study, the mass flow and removal efficiency of D5 in a sewage plant were reported, but the mass balance was neglected (Kazuyuki et al., 2007). In both studies, investigations of the volatile siloxane behavior were performed in a conventional activated sludge process. To the best of our knowledge, there is no report of the volatile siloxane behavior in the anaerobic-anoxic-oxic (traditional $\mathrm{A}^{2} / \mathrm{O}$ ) process or anoxic-anaerobic-oxic (reversed $\mathrm{A}^{2} / \mathrm{O}$ ) process, both of which were extensively utilized in municipal WWTPs.

In terms of sample matrices, residual levels of volatile cyclic and linear siloxanes have been analyzed in environmental matrices including air, soil, sludge, sediment, and biota. The analytical methods involved include solid phase extraction and organic solvent extraction/gas chromatography-mass spectrometry (GC-MS) and gas chromatography-atomic emission detection (GC-AED) (Warner et al., 2010; Sanchez-Brunete et al., 2010; Boehmer and Gerhards, 2003). Currently, there are only a few analytical methods of volatile siloxanes in aqueous samples, including gas stripping process (Huppmann et al., 1996), purge and trap GC-MS procedure (Kaj et al., 2005), and headspace gas chromatography with mass spectrometry (Sparham et al., 2008). Solid-phase microextraction (SPME) is a simple, economical, solventfree, and reliable method for the simultaneous determination of volatile organic compounds from aqueous samples (Stiles et al., 2008; Pazarro et al., 2010; Negreira et al., 2010; Dong et al., 2005). In this paper, SPME coupled with GC-MS is used to determine four cyclic and two linear volatile siloxanes in aqueous and sludge samples from a WWTP. Using the developed method, we report the determination of volatile siloxane concentrations in aqueous and sludge samples from different treatment units, and study their degradation characteristics in vitro. Finally, we carry out systematic analysis of the occurrence and migration of volatile siloxanes in secondary treatment processes of one WWTP in Beijing City of China.

\section{Materials and methods}

\subsection{Sampling collection}

The studied WWTP locates in the north of Beijing City, China, and has a capacity of $400,000 \mathrm{~m}^{3} / \mathrm{d}$ domestic wastewater. The catchment area of the WWTP covers about $159.42 \mathrm{~km}^{2}$, with a population of 810,000 . In the WWTP, primary treatments, including bar screens and grit chamber, are followed by two parallel secondary treatment processes including traditional $\mathrm{A}^{2} / \mathrm{O}$ and reversed $\mathrm{A}^{2} / \mathrm{O}$, each having a capacity of $200,000 \mathrm{~m}^{3} /$ $\mathrm{d}$ domestic wastewater.

In the traditional $\mathrm{A}^{2} / \mathrm{O}$ process, the hydraulic retention times in the anaerobic, anoxic and oxic tanks were 1.5, 3 and $10.8 \mathrm{~h}$, respectively. After settling in the secondary clarifier, part of the activated sludge was returned to the anaerobic tank, and the rest was conveyed to be dehydrated. The total solid retention time was $20-25 \mathrm{~d}$. While in the reversed $\mathrm{A}^{2} / \mathrm{O}$ process, the hydraulic retention times in anoxic, anaerobic and oxic tank were 1.5, 2.5 and $10.0 \mathrm{~h}$, respectively. The total solid retention time was $6-7 \mathrm{~d}$.

Two sampling events were carried out at the primary effluent (W1), secondary effluent (W5a and W5b), and outflows of different treatment processes in January and April, 2011 (Fig. 1). Using the methods described in a previous study (Guedez and Püttmann, 2011), 24 h composite samples were collected in a flow proportional mode. At equal time increments $(2 \mathrm{~h})$, samples were collected and composited with volume proportionally to the flow rate at the time of each sampling. Both composite aqueous and sludge-liquid samples were collected into $4 \mathrm{~L}$ glass bottles. Sludge-liquid samples from two secondary treatment processes were centrifuged at $3500 \mathrm{rpm}$ for $10 \mathrm{~min}$. The solid layer was collected as the sludge sample, and the liquid layer as the aqueous sample. Due to the ubiquity of siloxanes in the environment and in many consumer products, precautions were taken during sample collection. First, laboratory personnel participating in this study were forbidden to use any cosmetic products including hair mousses, styling gels, nail polishes, moisturizers, creams, lotions, etc. Second, no sampling or storage device during field collection was made of silica gel, and all devices were cleaned by chromatographygrade methanol. Third, field blank samples $(n=8)$ were prepared to assess ambient contamination during two samples events. Samples were stored at $4{ }^{\circ} \mathrm{C}$ using sealed containers with no headspace until sample pretreatment, which occurred within $48 \mathrm{~h}$ of the sample collection.

\subsection{Sampling preparation}

Reagents and materials used in our study were shown in the Supplementary material. M4Q has been widely used as an internal standard for analyzing both cyclic and linear siloxanes in various environmental matrices (Kannan, 2008; Sanchez-Brunete et al., 2010) because it is similar in chemical composition with siloxanes, hardly detectable in environment matrices and not interfering with siloxanes in the analysis. 


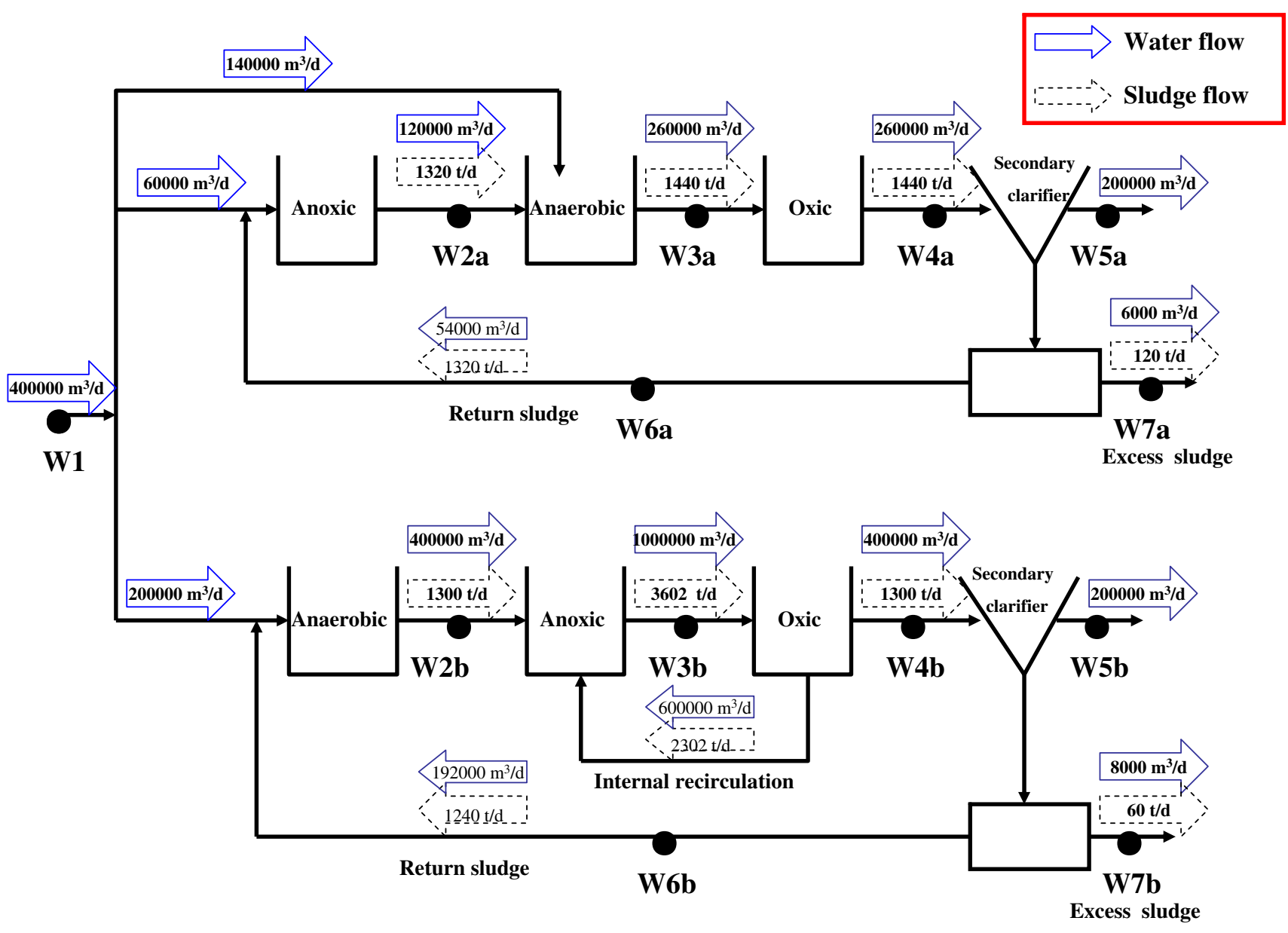

Fig. 1 - Flow scheme of the municipal WWTP with sampling locations.

\subsubsection{Water samples}

Because of the complicated matrix in the wastewater and high volatility of the analytes, headspace extraction (HS) mode was preferred for direct extraction. The optimum conditions were determined and listed as follows. Water sample $(40 \mathrm{~mL})$ was placed in a $60 \mathrm{~mL}$ headspace vial containing a magnetic stir bar. Into a vial were added $40 \mu \mathrm{L}$ of $500 \mu \mathrm{g} / \mathrm{L}$ tetrakis(trimethylsiloxy)silane (M4Q) as internal standard and $0.1 \mathrm{~g} / \mathrm{mL}$ sodium chloride $(\mathrm{NaCl})$, and then the vial was tightly sealed with a Teflon septum. HS-SPME with polydimethylsiloxane/ diviylbenzene (PDMS/DVB) fiber was carried out at $24{ }^{\circ} \mathrm{C}$ for $45 \mathrm{~min}$. After the extraction, the fiber was removed from the vial and inserted into the injection port of GC/MS system for thermal desorption and analysis. The detail of the GC/MS analysis can be found in the Supplementary material.

\subsubsection{Sludge samples}

Freeze-dried sludge sample $(0.2 \mathrm{~g})$, spiked with $20 \mathrm{ng}$ of M4Q as internal standard, was extracted with $3 \mathrm{~mL}$ acetone. After $30 \mathrm{~min}$ of ultrasonication, the mixture was centrifuged at $3500 \mathrm{rpm}$ for $5 \mathrm{~min}$. The supernatant was transferred to a $60-\mathrm{mL}$ headspace vial. The extraction procedure was repeated three times. Then the final solution was evaporated to about $200 \mu \mathrm{L}$ under a gentle nitrogen stream, followed by a dilution with $40 \mathrm{~mL}$ ultrapure water. The resulting solution was then treated in the same fashion as the wastewater.

\subsection{Mass balance calculation}

Mass flux (W) was calculated using as the following equation.

$\mathrm{W}=\mathrm{C}_{\text {water }} \times \mathrm{Q}_{\text {water }}+\mathrm{C}_{\mathrm{AS}} \times \mathrm{Q}_{\text {water }} \times \mathrm{C}_{\mathrm{TTS}}$

where $C_{\text {water }}, C_{\mathrm{AS}}$, and $C_{\mathrm{TTS}}$ represent the target compound concentration in water, activated sludge (dry weight), and concentration of total suspended solids, respectively. $Q_{\text {water }}$ is the water flow rate.

The relative fraction (\%) of mass loss (RFML) in each secondary treatment unit was calculated using the following equation.

$\mathrm{RFML}=\left(\mathrm{W}_{\text {Inflow }}-\mathrm{W}_{\text {Outflow }}\right) /\left(\mathrm{W}_{\text {Prieff }}-\mathrm{W}_{\text {Seceff }}\right) \times 100 \%$

where $\mathrm{W}_{\text {Outflow }}$ and $\mathrm{W}_{\text {Inflow }}$ represent the mass flux of target compound in outflow and inflow of each treatment unit, while $W_{\text {Prieff }}$ and $W_{\text {Seceff }}$ represent the mass flux of target compound in primary effluent and secondary effluent of the studied WWTP.

In order to assess the contribution of sludge sorption to eliminating volatile siloxanes in the WWTP, the relative 
fraction (\%) of mass loss by sorption (RFML lated by the following equation:

$$
\begin{aligned}
\mathrm{RFML}_{\text {Sludge }}= & \left(C_{\mathrm{ES}} \times \mathrm{Q}_{\mathrm{ES}} \times C_{\mathrm{TTS}}+C_{\text {Water }} \times \mathrm{Q}_{\mathrm{ES}}\right) /\left(C_{\text {Prieff }}-C_{\text {Seceff }}\right) \\
& \times \mathrm{Q}_{\text {Water }}
\end{aligned}
$$

where $C_{\mathrm{ES}}, \mathrm{C}_{\mathrm{TTS}}, \mathrm{C}_{\text {Water }}, \mathrm{C}_{\text {Prieff }}$, and $\mathrm{C}_{\text {Seceff }}$ represent the target compound concentration desorbed in suspended solids of excess sludge (dry weight), concentration of total suspended solids in excess sludge, dissolved concentration in aqueous phase of excess sludge, and concentration in primary effluent and secondary effluent, respectively. $Q_{W}$ ater and $\mathrm{Q}_{E S}$ are the water and excess sludge flow.

\subsection{In vitro study for anaerobic degradation of volatile cyclic siloxanes (D3-D6)}

In a typical batch test setting, each glass vial $(60 \mathrm{~mL})$ contained $40 \mathrm{~mL}$ of activated sludge-liquid mixture (10 g of dry solid per liter, $\mathrm{pH}=6.5-6.8$ ) as the culture, which was obtained from the anaerobic tank of the studied WWTP. Accounting for volatilization of cyclic siloxanes, each glass vial was sealed with a Teflon septum, and the headspace of the sealed vial was connected with another glass vial containing $5 \mathrm{~mL}$ acetone through a Teflon tube ( $2 \mathrm{~mm}$, inner diameter) to absorb the siloxanes via volatilization from the culture. And then the solutions of four volatile cyclic siloxanes were spiked with the culture at three concentration levels (2.0, 5.0, and $10.0 \mu \mathrm{g} / \mathrm{L})$ via injection, respectively. The cultures were incubated under a headspace of $\mathrm{N}_{2} / \mathrm{CO}_{2}(80: 20,1 \mathrm{~atm})$ at $30{ }^{\circ} \mathrm{C}$, while being shaken at $300 \mathrm{rpm}$. For each spiked concentration level, fifteen test vials were established, and at each of the following time points $(0,10,20,40$, and $60 \mathrm{~h})$, three vials were taken to determine the total mass loss of volatile cyclic siloxanes in the culture and acetone solvent (Fig. S2), respectively. Dissolved organic carbon (DOC) in the culture was also detected to indicate the anaerobic reaction activity. In all cultures, the DOC concentrations were reduced in the range of $42-65 \%$ after 60 h. Meanwhile, as the control group, glass vials containing sterile sludges (sterilized by $1 \% \mathrm{NaN}_{3}$ ) were prepared and tested (Fig. S2).

\section{Results and discussion}

\subsection{Method validation}

The correlation coefficients $\left(R^{2}\right)$ of six target compounds varied between 0.9922 and 0.9997 in linear ranges $(0.05-10 \mu \mathrm{g} /$ L) in standard ultrapure aqueous solutions. The method detection limits (MDLs) of siloxanes in ultrapure water were calculated with the EPA method, which were 3.14 times standard deviations of the detected concentrations $(n=7)$ at lower spiked levels (about five times the MDL), ranging from 2.6 to $7.8 \mathrm{ng} / \mathrm{L}$ (Table S2). The repeatability of the method was expressed by relative standard deviation (RSD, \%) of the peak area, which was calculated from the values in five measurements at two concentration levels (0.1 and $5.0 \mu \mathrm{g} / \mathrm{L})$. The results were in the range of $1.1-7.9 \%$ (Table S2). Recovery experiments were performed by spiking a mixture of six target compounds at three concentration levels $(0.5,1.0$ and $5.0 \mu \mathrm{g} / \mathrm{L})$ into the water samples. In consideration of high volatility, siloxane spiking (including the internal standard) was carried out using the appropriate microliter syringes with the needle inserted deeply below the liquid surface, followed by the addition of sodium chloride immediately. Then the headspace vials were rapidly capped in preparation for analysis. Table S3 shows the good recovery for the six compounds (78-96\%).

MDLs of most target compounds in the sludge samples were below $1 \mathrm{ng} / \mathrm{g}$. The relative standard deviations (RSD, \%) of the peak area at two concentration levels $(20 \mathrm{ng} / \mathrm{g}$ and $200 \mathrm{ng} /$ g) were in the range of $2.1-7.3$ (Table S2). Recoveries of six compounds ranged from $75 \%$ to $93 \%$ at three spiked concentration levels (20, 50 and $200 \mathrm{ng} / \mathrm{g}$, Table S3).

\subsection{Matrix effect}

The matrix effect is significant in the aqueous and sludge samples. To investigate the matrix effect, four aqueous samples (ultrapure water, influent of WWTP, wastewater of anaerobic tank, and active sludge extract solution) were spiked at three concentration levels $(0.1,1.0$, and $5.0 \mu \mathrm{g} / \mathrm{L})$. Compared to the ultrapure water, signal suppression of six target compounds, as calculated by $(1-A / B) \times 100 \%$ (where $A$ and $B$ represent the peak areas of the target compounds gained from environment aqueous sample and ultrapure water sample, respectively), was apparent (12-41\%) in environmental aqueous samples (Table S4). This may be because dissolved and suspended organic matters, i.e. humic acid, proteins, and fats, in these samples increased the partition coefficients of volatile siloxanes in water and decreased their release rates to gas phase (Whelan et al., 2009). MDLs of siloxanes in the influent of WWTP and wastewater of anaerobic tank samples ranged from 3.1 to $10.2 \mathrm{ng} / \mathrm{L}$ (Table S5), which were higher than those in ultrapure water. For the six volatile siloxanes, relative standard deviations of external calibration equation slopes in different matrices were 17.4-26.2\% (Table S6), suggesting that quantification using external calibration for target compounds had systematic errors due to the matrix effect. Using M4Q as the internal standard significantly minimized the matrix effect as shown by the low relative standard deviations in the range of $2.4-3.8 \%$.

Degradation of the PDMS/DVB fiber coating could decrease the extraction efficiency in the SPME. Furthermore, the polydimethylsiloxanes, a major constituent of the studied fiber coating, may thermally degrade to siloxanes causing falsely high reading. Laboratory blank runs (ultrapure water, containing $500 \mathrm{ng} / \mathrm{L}$ of internal standard) were carried out every time after running 20 environmental samples. In the initial experiments, there was no interfering peak at the same retention time as the target compounds. Even after about 100 runs of the SPME, interfering peak areas for all target compounds were less than $20 \%$ of those of their MDLs. This indicated our method had merely slight interference with the low operating temperatures $\left(24^{\circ} \mathrm{C}\right.$ for adsorption temperature, and $200^{\circ} \mathrm{C}$ for desorption temperature). Additionally, the extraction efficiency was studied by comparing the peak areas of internal standards. After 120 runs, the extraction efficiency of internal standard was reduced by over $10 \%$, indicating the 
ability of the fiber to extract target compounds had been compromised, and the fiber coating should be replaced.

\subsection{Volatile siloxanes occurrence in aqueous phase of the WWTP}

Compared to laboratory blanks, there was no larger baseline signal or peak area of target compounds in eight field blanks, indicating that siloxane contaminations during the field collection in our study could be neglected. For two linear siloxanes, L3 was not found in any of the analyzed aqueous samples, while L4 was barely detectable in the influent and the anaerobic samples of reversed $\mathrm{A}^{2} / \mathrm{O}$ process in January of 2011 (0.07 and $0.21 \mu \mathrm{g} / \mathrm{L}$ respectively). Conversely, cyclic siloxanes, which are mainly used in cosmetics and health care products, had much higher detection frequencies and concentration levels (Table 1). D4, D5, and D6 were detected in all wastewater samples during both sampling events at 0.05-4.30 $\mu \mathrm{g} / \mathrm{L}, 0.07-7.60 \mu \mathrm{g} / \mathrm{L}$, and $0.05-7.13 \mu \mathrm{g} / \mathrm{L}$, respectively. D3 was detected with concentrations ranging from 0.07 to $0.59 \mu \mathrm{g} / \mathrm{L}$ in all samples except the secondary effluent of traditional $\mathrm{A}^{2} / \mathrm{O}$ treatment processes in April of 2011.

In general, secondary effluent samples contained relatively lower concentrations of D3, D4, D5, and D6 than primary effluent samples (Table 1). Their removal efficiencies in the secondary treatments (average values from the two sampling events), calculated by comparing the concentration in the secondary effluent and primary effluent, were in the range of $76.2-92.7 \%$ in the traditional $\mathrm{A}^{2} / \mathrm{O}$ process and $59.3-80.6 \%$ in the reversed $\mathrm{A}^{2} / \mathrm{O}$ process (Fig. S1). However, D4, D5, and D6 in both anaerobic unit of traditional $\mathrm{A}^{2} / \mathrm{O}$ processes and anoxic unit of reversed $\mathrm{A}^{2} / \mathrm{O}$ processes had higher concentrations (Table 1) than those in primary effluent samples. It is possible that the return sludge first entered the above two units in these two $\mathrm{A}^{2} / \mathrm{O}$ processes (Fig. 1), where siloxanes compounds adsorbed in the return sludge would re-enter the aqueous phase via agitation (detailed explanation is discussed in Section 3.5.1).

\subsection{Volatile cyclic siloxane emission to the environment in the catchment area of the WWTP}

In the catchment area of the WWTP, which is located in a residential-intensive area, volatile cyclic siloxane (D3, D4, D5, and D6) residues were assumed to come mainly from personal care and household products used by the general public. Concentrations of cyclic siloxanes at all sampling sites showed no significant variations between two sampling events ( $p>0.05$, T test), suggesting stable emissions to the wastewater in the catchment area. The mass loading (kg/year) in the primary effluent was obtained by multiplying the average target compound concentration of the two sampling events with the annual influent volume. The calculated results for D3, D4, D5, and D6 were 78.2, 387.7, 462.1, and $347.5 \mathrm{~kg} /$ year, respectively.

Assuming the D4, D5, and D6 emissions (no available data for D3) to environment from the above source are $90 \%$ to the air and $10 \%$ to the wastewater (EA, 2009a,b,c), the annual target emission to the environment per capita in this residential area could be calculated by dividing mass loading in the primary effluent by the population $(810,000)$, and then multiplying by 10 . The calculated results for D4, D5, and D6 were $4.8,5.7$, and $4.3 \mathrm{~g} /$ year respectively. The total emissions of the three targets (14.8 g/year per capita) were higher than $10 \mathrm{~g} /$ year as reported as the total siloxanes (including both cyclic and linear siloxanes) usage per capita in Chinese (Zhou et al., 2009). This result may be due to the higher consumption rate of personal care and household products in the studied region - one of the most developed cities in China compared to most other regions. In addition, it was estimated that emissions of D4, D5 and D6 in personal care products were about $1.4,42$, and 4.9 g/year per capita respectively in UK (EA, 2009a,b,c), and 0.4, 85, and $8.1 \mathrm{~g} /$ year per capita in the USA [calculated with data in Ref (Kannan, 2008)]. Comparing with these two developed countries, the emission of D4 is higher in the studied region, while that of D5 is lower. The emission of D6 is comparable among the countries. This result perhaps indicated different consumption patterns of personal care and household products in these countries. It should be noted that the analysis was not performed on raw wastewater sample underground or in the pipe sealing but primary effluent. The emissions of target compounds calculated by mass loading of the primary effluent would be lower than the actual values due to the mass loss during the primary treatment (bar screens and grit chamber).

\subsection{Fate of volatile siloxanes along secondary treatment processes}

\subsubsection{Target compound removal by sorption at secondary treatment processes}

To clarify the removal mechanisms of volatile siloxanes (D3, D4, D5 and D6) in the WWTP, the fractions (\%) of mass loss were studied in the four basic treatment units of each secondary treatment process, including the activated sludge system (anaerobic, anoxic, and oxic tanks) and the secondary clarifier. The mass balance results for each target compound (Fig. 2) were expressed in relative fractions (\%) of mass loss due to the removal in each secondary treatment unit, and sorption to excess sludge relative to the total mass loss $\left(W_{\text {prieff }}-W_{\text {Seceff }}\right)$.

For D3, D4, D5, and D6 (average value from the two sampling events), relative fractions of mass loss by sorption to excess sludge in traditional $\mathrm{A}^{2} / \mathrm{O}$ process were $8.3 \pm 1.8 \%$, $29.4 \pm 2.8 \%, 38.1 \pm 7.2 \%$, and $53.0 \pm 13.5 \%$ respectively, and $9.8 \pm 1.4 \%, 19.0 \pm 1.3 \%, 32.0 \pm 2.3 \%$, and $40.2 \pm 6.0 \%$ respectively in reversed $\mathrm{A}^{2} / \mathrm{O}$ process (calculated from Equation (3)). Due to their high octanol/water partition coefficients [such as 5.1 for D4, 5.2 for D5, and 5.86 for D6 (EA, 2009a,b,c), express as logarithmic values], previous studies indicated that cyclic siloxanes were prone to adsorbing on sediment/sludge in aquatic environment. In our study, the partitioning coefficient (PC) was introduced to indicate the sorption characteristics of volatile siloxanes, and calculated as the ratio of the concentration in the activated sludge to the concentration in the overlying wastewater. Generally, PC values (L/kg) of D3, D4, D5, and D6 ranged from 142 to 1835,136 to 4869,162 to 4667 , and 114 to 6814, respectively (Table S7), suggesting their strong adsorption to sludge. 
Table 1 - Volatile siloxane concentrations data (aqueous and sludge samples).

\begin{tabular}{|c|c|c|c|c|c|c|c|}
\hline & & D3 & D4 & D5 & D6 & L3 & L4 \\
\hline \multirow[t]{13}{*}{ Aqueous, January $2011(\mu \mathrm{g} / \mathrm{L})$} & W1 & 0.48 & 2.89 & 3.29 & 2.20 & $\mathrm{nd}^{\mathrm{a}}$ & 0.07 \\
\hline & W2a & 0.47 & 3.59 & 4.43 & 5.68 & nd & 0.21 \\
\hline & W3a & 0.25 & 2.92 & 2.96 & 3.10 & nd & nd \\
\hline & W4a & 0.22 & 2.07 & 3.79 & 3.62 & nd & nd \\
\hline & W5a & 0.09 & 0.55 & 0.78 & 0.96 & nd & nd \\
\hline & W6a & nd & 0.09 & 0.07 & 0.12 & nd & nd \\
\hline & W7a & nd & 0.09 & 0.07 & 0.12 & nd & nd \\
\hline & W2b & 0.32 & 4.30 & 5.13 & 7.13 & nd & nd \\
\hline & W3b & 0.30 & 4.00 & 5.24 & 6.84 & nd & nd \\
\hline & W4b & 0.26 & 3.86 & 4.97 & 6.75 & nd & nd \\
\hline & W5b & 0.07 & 0.45 & 0.62 & 0.52 & nd & nd \\
\hline & W6b & nd & 0.10 & 0.11 & 0.08 & nd & nd \\
\hline & W7b & nd & 0.10 & 0.11 & 0.08 & nd & nd \\
\hline \multirow[t]{13}{*}{ Aqueous, April 2011 ( $\mu \mathrm{g} / \mathrm{L})$} & W1 & 0.59 & 2.42 & 3.04 & 2.56 & nd & nd \\
\hline & W2a & 0.40 & 3.33 & 5.40 & 5.55 & nd & nd \\
\hline & W3a & 0.21 & 2.88 & 3.03 & 3.14 & nd & nd \\
\hline & W4a & 0.19 & 2.14 & 4.03 & 3.67 & nd & nd \\
\hline & W5a & 0.12 & 0.53 & 1.00 & 0.96 & nd & nd \\
\hline & W6a & nd & 0.12 & 0.11 & 0.04 & nd & nd \\
\hline & W7a & nd & 0.12 & 0.11 & 0.04 & nd & nd \\
\hline & $\mathrm{W} 2 \mathrm{~b}$ & 0.30 & 4.04 & 7.60 & 5.52 & nd & nd \\
\hline & W3b & 0.29 & 3.85 & 7.48 & 4.98 & nd & nd \\
\hline & W4b & 0.26 & 3.62 & 7.18 & 4.74 & nd & nd \\
\hline & W5b & nd & 0.25 & 0.50 & 0.62 & nd & nd \\
\hline & w6b & nd & 0.05 & 0.07 & 0.05 & nd & nd \\
\hline & W7b & nd & 0.05 & 0.07 & 0.05 & nd & nd \\
\hline \multirow[t]{12}{*}{ Sludge, January 2011 (ng/g) } & W2a & $4.5 \times 10^{1}$ & $4.1 \times 10^{2}$ & $9.5 \times 10^{2}$ & $4.5 \times 10^{2}$ & nd & $1.8 \times 10^{2}$ \\
\hline & W3a & $4.2 \times 10^{1}$ & $2.6 \times 10^{2}$ & $8.4 \times 10^{2}$ & $4.6 \times 10^{2}$ & nd & nd \\
\hline & W4a & $4.5 \times 10^{1}$ & $4.1 \times 10^{2}$ & $6.9 \times 10^{2}$ & $3.6 \times 10^{2}$ & nd & nd \\
\hline & W5a & $7.0 \times 10^{1}$ & $7.0 \times 10^{2}$ & $1.3 \times 10^{3}$ & $9.1 \times 10^{2}$ & nd & nd \\
\hline & W6a & $7.0 \times 10^{1}$ & $7.0 \times 10^{2}$ & $1.3 \times 10^{3}$ & $9.1 \times 10^{2}$ & nd & nd \\
\hline & W7a & $7.0 \times 10^{1}$ & $7.0 \times 10^{2}$ & $1.3 \times 10^{3}$ & $9.1 \times 10^{2}$ & nd & nd \\
\hline & W2b & $4.5 \times 10^{1}$ & $9.9 \times 10^{2}$ & $1.5 \times 10^{3}$ & $1.4 \times 10^{3}$ & nd & nd \\
\hline & W3b & $5.0 \times 10^{1}$ & $1.0 \times 10^{3}$ & $1.4 \times 10^{3}$ & $1.5 \times 10^{3}$ & nd & nd \\
\hline & $\mathrm{W} 4 \mathrm{~b}$ & $6.1 \times 10^{1}$ & $1.1 \times 10^{3}$ & $1.5 \times 10^{3}$ & $1.5 \times 10^{3}$ & nd & nd \\
\hline & W5b & $1.3 \times 10^{2}$ & $2.2 \times 10^{3}$ & $2.9 \times 10^{3}$ & $3.5 \times 10^{3}$ & nd & nd \\
\hline & W6b & $1.3 \times 10^{2}$ & $2.2 \times 10^{3}$ & $2.9 \times 10^{3}$ & $3.5 \times 10^{3}$ & nd & nd \\
\hline & W7b & $1.3 \times 10^{2}$ & $2.2 \times 10^{3}$ & $2.9 \times 10^{3}$ & $3.5 \times 10^{3}$ & nd & nd \\
\hline \multirow[t]{12}{*}{ Sludge, April 2011 (ng/g) } & W2a & $6.5 \times 10^{1}$ & $4.6 \times 10^{2}$ & $8.8 \times 10^{2}$ & $6.4 \times 10^{2}$ & nd & nd \\
\hline & W3a & $6.5 \times 10^{1}$ & $2.6 \times 10^{2}$ & $9.1 \times 10^{2}$ & $6.7 \times 10^{2}$ & nd & nd \\
\hline & W4a & $6.0 \times 10^{1}$ & $3.7 \times 10^{2}$ & $6.5 \times 10^{2}$ & $5.1 \times 10^{2}$ & nd & nd \\
\hline & W5a & $7.5 \times 10^{1}$ & $6.8 \times 10^{2}$ & $1.2 \times 10^{3}$ & $1.0 \times 10^{3}$ & nd & nd \\
\hline & W6a & $7.5 \times 10^{1}$ & $6.8 \times 10^{2}$ & $1.2 \times 10^{3}$ & $1.0 \times 10^{3}$ & nd & nd \\
\hline & W7a & $7.5 \times 10^{1}$ & $6.8 \times 10^{2}$ & $1.2 \times 10^{3}$ & $1.0 \times 10^{3}$ & nd & nd \\
\hline & W2b & $5.5 \times 10^{1}$ & $1.1 \times 10^{3}$ & $1.4 \times 10^{3}$ & $1.2 \times 10^{3}$ & nd & nd \\
\hline & W3b & $5.6 \times 10^{1}$ & $1.1 \times 10^{3}$ & $1.4 \times 10^{3}$ & $1.4 \times 10^{3}$ & nd & nd \\
\hline & W4b & $6.5 \times 10^{1}$ & $1.2 \times 10^{3}$ & $1.5 \times 10^{3}$ & $1.5 \times 10^{3}$ & nd & nd \\
\hline & W5b & $1.3 \times 10^{2}$ & $2.3 \times 10^{3}$ & $3.7 \times 10^{3}$ & $2.8 \times 10^{3}$ & nd & nd \\
\hline & W6b & $1.3 \times 10^{2}$ & $2.3 \times 10^{3}$ & $3.7 \times 10^{3}$ & $2.8 \times 10^{3}$ & nd & nd \\
\hline & W7b & $1.3 \times 10^{2}$ & $2.3 \times 10^{3}$ & $3.7 \times 10^{3}$ & $2.8 \times 10^{3}$ & nd & nd \\
\hline
\end{tabular}

a Not detected.

In different treatment units, PC values of volatile cyclic siloxanes differed significantly ( $p<0.05$, Friedman Test), which may be attributed to varied organic matters distributions. In the activated sludge system, the wastewater mixed with the activated sludge via agitation, and then the dissolved organic matter (DOM) from the activated sludge may enter the aqueous phase. The DOM would elevate the dissolved concentrations of the non-polar compounds by enhancing water solubility and aggravating their desorption from the activated sludge, thus reduce their PC values (Song et al., 2006; Luo et al., 2011). In this paper, DOM concentrations at various tanks of both secondary treatment processes were detected with a Shimadzu TOC5000 analyzer (Table S8). Except for $\mathrm{D} 5$ in traditional $\mathrm{A}^{2} / \mathrm{O}$ process, significantly negative correlations existed between log PC values and the DOC concentrations at each secondary treatment process (Fig. 3). The above result showed that a significant amount of volatile cyclic siloxanes could partition in the DOM in the 

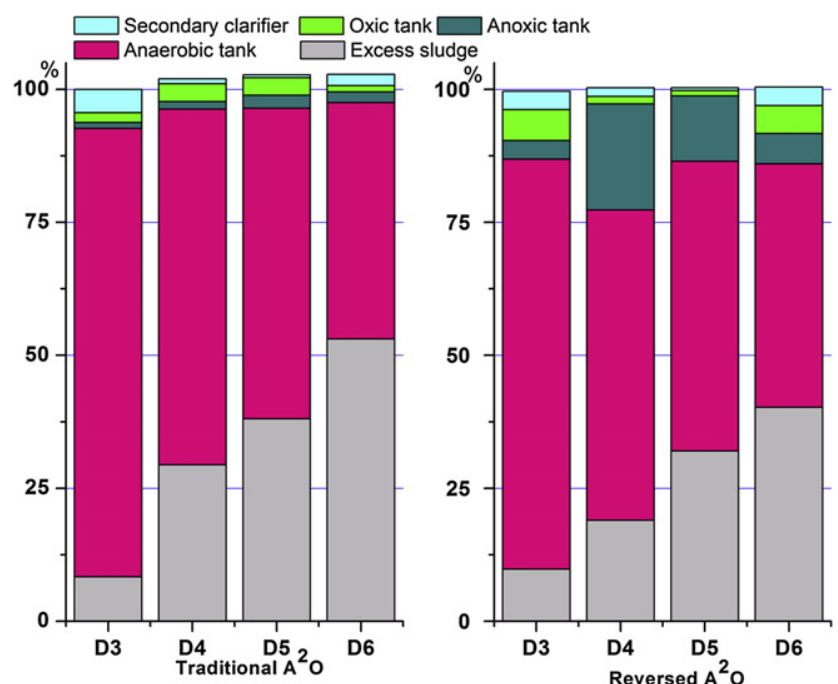

Fig. 2 - Relative fractions of mass loss for volatile cyclic siloxanes due to the adsorption to excess sludge, and elimination in each secondary treatment unit (average values from the two sampling events).

aqueous phase, which lead to their significantly elevated migration capacity in the WWTP. Evidently, increased DOM concentrations in the influent would result in higher fractions of cyclic volatile siloxanes in the treated effluent, and thus increase the risk for the aquatic ecosystems in the discharge areas.

\subsubsection{Target compound elimination along each unit of} secondary treatment processes

Besides the sorption to excess sludge, we also studied the elimination (possibly via volatilization and degradation) of volatile siloxanes along the units of secondary treatment processes. In the anaerobic tank of the traditional $\mathrm{A}^{2} / \mathrm{O}$ process, relative fractions of mass loss for D3, D4, D5, and D6 were in the range of $44.4-84.3 \%$, while the total relative fractions in the anoxic, oxic tanks and secondary clarifier were in the range of $6.3-7.4 \%$ (calculated by Equation (2)). In the reversed $A^{2} / O$ process, relative fractions of mass loss for $D 3$, $\mathrm{D} 4, \mathrm{D} 5$, and $\mathrm{D} 6$ in anaerobic tank were in the range of 45.8-77.1\%, while the total in the other units were $12.7-22.9 \%$ (Fig. 2). The above results indicated that in both traditional and reversed $\mathrm{A}^{2} / \mathrm{O}$ processes, volatile siloxanes were mostly eliminated in the anaerobic tanks.

To the best of our knowledge, there is no report on the elimination mechanism of the volatile siloxanes in anaerobic aqueous environment. In our study, as showed in Section 2.4, an in vitro digestion system was created to study volatilization and degradation of cyclic volatile siloxanes (D3, D4, D5, and D6) at three spiked concentration levels (2.0, 5.0, and $10.0 \mu \mathrm{g} /$ L). In the sterile system, for each compound, the total mass in liquid-sludge mixture and gas phase was approximately stable during the incubation events $(60 \mathrm{~h})$, indicating that
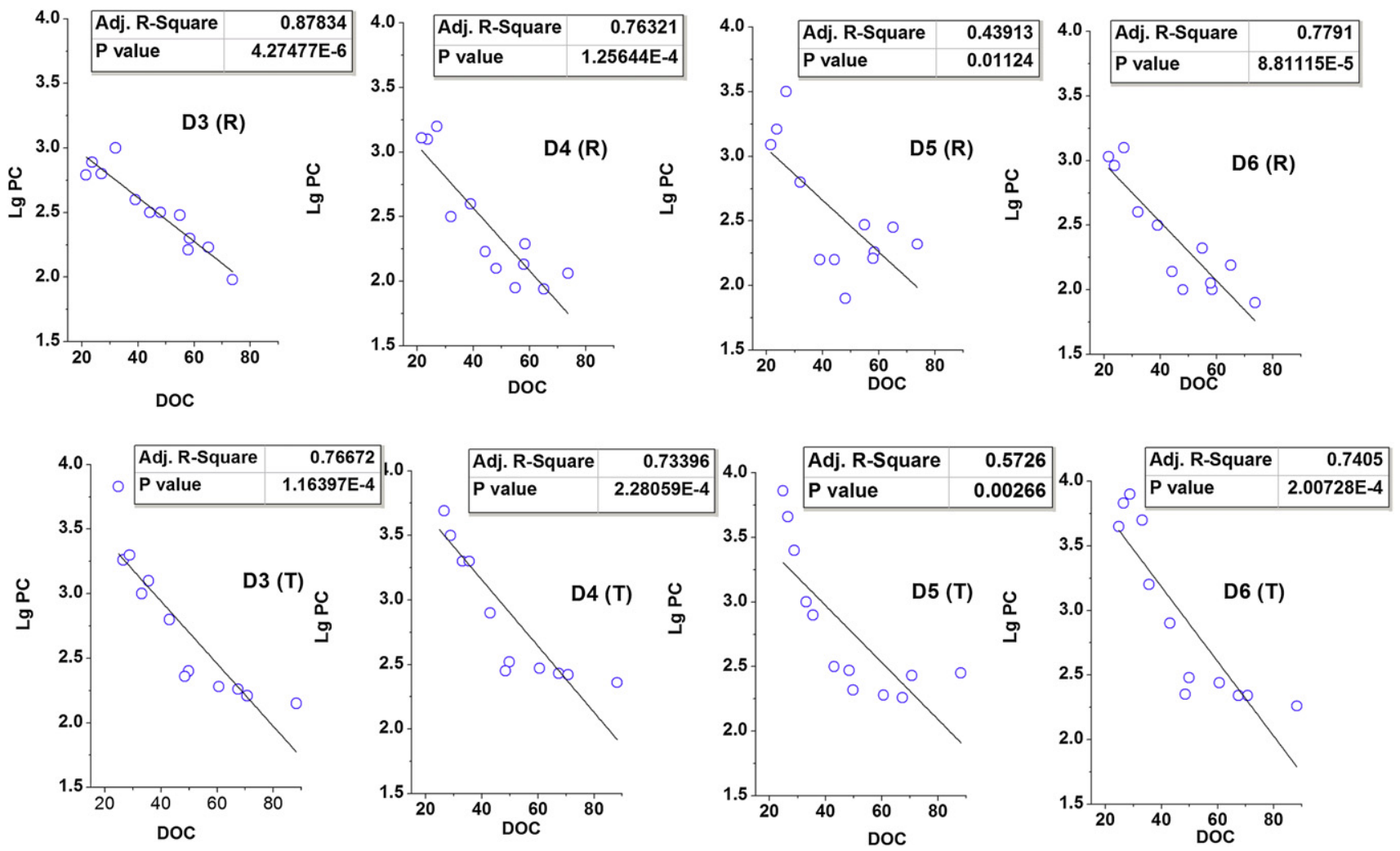

Fig. 3 - Correlation between log PC values of the volatile cyclic siloxanes and the DOC concentrations ( $\mathrm{mg} / \mathrm{L}$ ) of aqueous samples $(n=12$ ), including eight samples from W2a-W5a (or W2b-W5b) units during the two sampling events, and four additional samples prepared by mixing samples from different units. (T) represents the traditional $A^{2} / O$ process, while (R) presents the reversed $A^{2} / O$ process. 
cyclic siloxanes are not prone to degradation without microbe catalysis (Fig. S2).

In the activated system, D3 and D6 hardly biodegraded after $10 \mathrm{~h}$ (0.5-1.8\%), and only biodegraded slightly (3.0-18.1\%) after $60 \mathrm{~h}$ (Fig. 4). Considering the short hydraulic retention times in the anaerobic tanks of both tradition (1.5 h) and reversed $(2.5 \mathrm{~h}) \mathrm{A}^{2} / O$ processes in the studied WWTP, it is concluded that degradation of D3 and D6 is minimal in the anaerobic tanks and their elimination mechanism is through volatilization. The reason why the majority of D3 and D6 were removed in the anaerobic tanks is as follows. On one hand, in the two parallel secondary treatment processes, most of the effluent of the primary treatment processes first entered the anaerobic tanks $\left(100 \%\right.$ for $\mathrm{A}^{2} / \mathrm{O}$ process, and $70 \%$ for reversed $\mathrm{A}^{2} / \mathrm{O}$ process). Volatile siloxanes from the effluent of the primary treatment processes and return sludge would volatilize first via agitation in the anaerobic tanks. On the other hand, a portion of the volatile siloxanes was prone to enter biogas of the anaerobic tank and then be removed by a threephase separator (Mirsepasi et al., 2006). Our conclusion about the fate of D6 in the anaerobic tanks is different from a previous literature (Dewil et al., 2007) which reported that D6 did not volatilize during sludge anaerobic digestion due to the adsorption in the sludge. The discrepancy may be explained as follows. The solid content (about 1\%) in the anaerobic tanks of $\mathrm{A}^{2} / \mathrm{O}$ process was much lower than that in the sludge anaerobic digestion (3-6\%) (Appels et al., 2008), which could decrease the sludge adsorption capacity of D6 and increase its volatilization from the sludge.

Furthermore, Fig. 4 shows that much more fractions of D3 compared to other samples spiked into the sludge-liquid mixture entered the gas phase $(57 \%$ after $10 \mathrm{~h}$, and $81 \%$ after $60 \mathrm{~h}$, average value), indicating that poor biodegradation of D3 in the anaerobic systems may be caused by its high volatility from the activated sludge. For the four analogs (D3-D6), their volatilities decreased with increasing number of $\mathrm{Si}-\mathrm{O}$ bonds (CES, 2005). The lower fractions of D6 in the gas phase $(18 \%$ after $10 \mathrm{~h}$, and $26 \%$ after $60 \mathrm{~h}$, average value) indicate that not volatilization but poor bioavailability mainly caused its poor biodegradation in the anaerobic system.

Compared with D3 and D6, D4 and D5 were prone to degrade in the activated system. They degraded about 9.1-32.7\% after $10 \mathrm{~h}$, and 44.4-62.8\% after $60 \mathrm{~h}$ (Fig. 4). Anaerobic degradation pathways of cyclic siloxanes were not investigated systematically in our present study. However, dimethylsilanediol $\left[\mathrm{Me}_{2} \mathrm{Si}(\mathrm{OH})_{2}\right]$, one of their hydrolyzates (Varaprath et al., 1999; Dow Corning, 2005) was found in the activated sludge-liquid mixture by solid phase extraction (SPE) coupled with derivative GC/MS (detailed procedure can be found in the Supplementary material). After incubation for $60 \mathrm{~h}$, about $21.4-30.6 \%$ (calculated as silicon mass, Fig. 5) of degraded D4 and D5 was found to have been transformed to dimethylsilanediol. Since hydrolyzates of siloxanes are not only dimethylsilanediol but also analogs of dimethylsiloxane$\alpha, \omega$-diols [HO( $\left.\mathrm{Me}_{2} \mathrm{SiO}\right) \mathrm{nH}$, with $\left.n=1-5\right]$ (EA, 2009a,b,c), it can be concluded that microbe catalysis hydrolysis may be one of the main degradation pathways for cyclic siloxanes in anaerobic tanks. The above conclusion can explain the phenomenon that D6 had poorer degradation than D4 and D5 in the anaerobic unit. It was reported that hydrolysis rates of D4-D6 in aqueous phase decreased with the increase in chain length mainly due to steric hindrance (EA, 2009a,b,c). Furthermore, portions of D4 and D5 (24-27\% after $10 \mathrm{~h}$, $33-42 \%$ after $60 \mathrm{~h}$ ) in the gas phase during the experiments, as shown in Fig. 4, indicate that D4 and D5 may be removed by both volatilization and degradation in the anaerobic units.

Volatile siloxanes hardly degrade in an oxic aquatic environment (EA, 2009a,b,c). Their eliminations in the oxic tanks
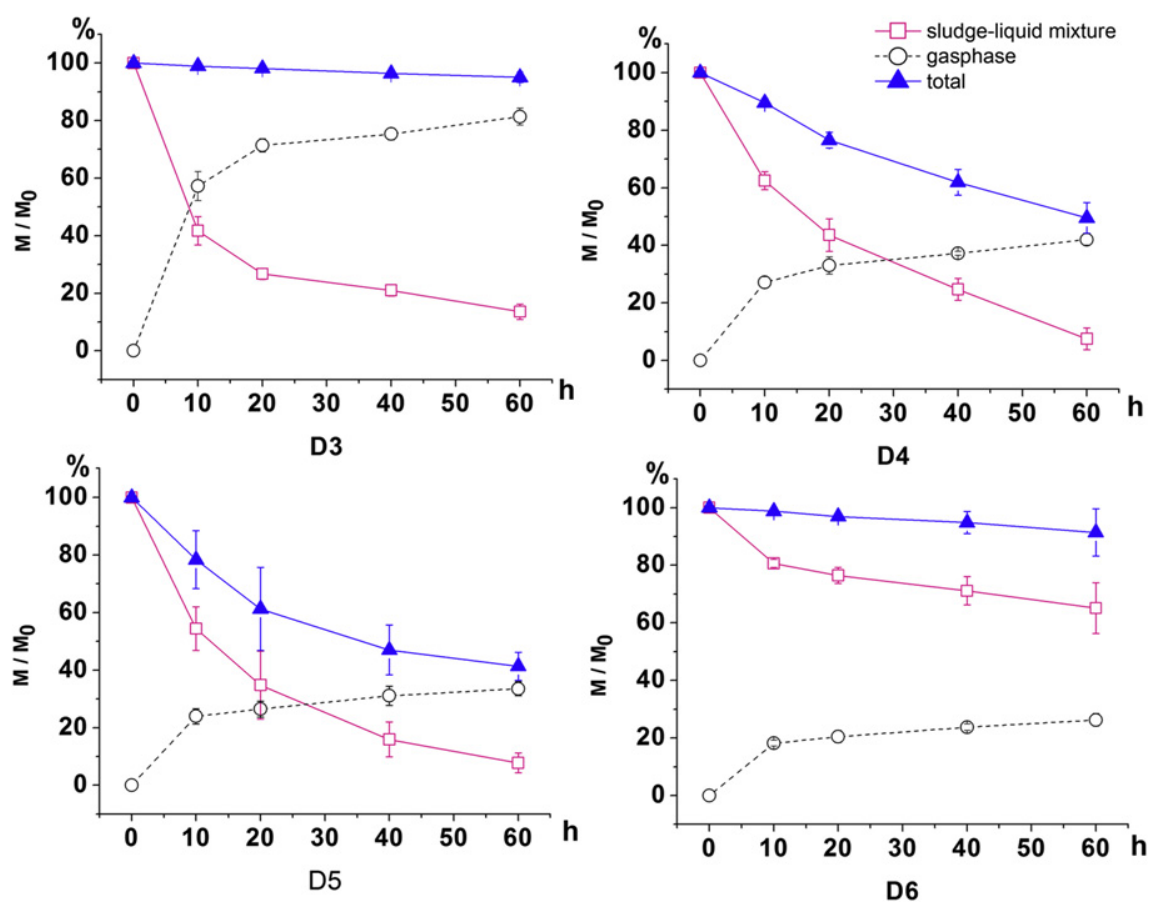

Fig. 4 - Siloxane mass fractions in the activated sludge-liquid mixture and gas phase, and total fractions relative to the initial spiked mass (average value at three spiked levels) during the anaerobic degradation experiment. 


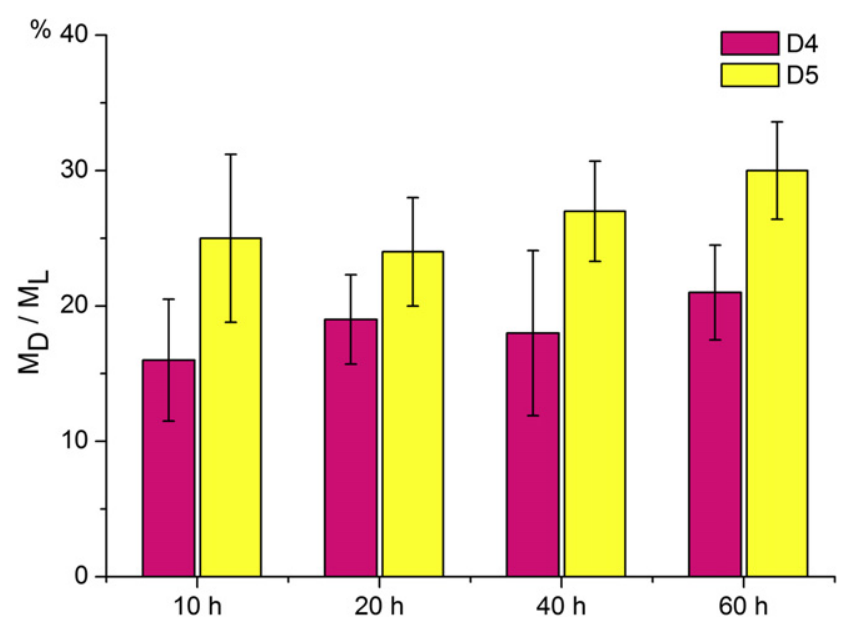

Fig. 5 - Siloxane mass fractions degraded to dimethylsilanediol $\left(M_{D}\right)$ relative to total mass loss due to degradation $\left(M_{L}\right)$ in the activated sludge-liquid mixture.

and secondary clarifiers were also caused by volatilization. In the anoxic tank of traditional $\mathrm{A}^{2} / \mathrm{O}$ process, the low relative fractions of mass loss for D3, D4, D5, and D6 (1.1-2.2\%, Fig. 2) indicates their weak anoxic biodegradation. For D3, D4, D5, and $D 6$, relative fractions of mass loss in the anoxic tank of the reversed $A^{2} / O$ process (3.5-19.9\%) were higher than those in the traditional $A^{2} / O$ process. It is estimated that in the reversed $A^{2} / O$ process, $30 \%$ of the effluent of the primary treatment processes first entered the anoxic tank, and would volatilize first via agitation in this tank (Fig. 1).

\section{Conclusion}

This first comprehensive investigation on volatile siloxanes in $\mathrm{A}^{2} / O$ processes of municipal WWTPs has shown that D3, D4, D5, and D6 were ubiquitous in both wastewater and sludge samples. The removal efficiency of the four compounds varied from 59.3 to $92.7 \%$. Besides adsorption, D3, D4, D5, and D6 were eliminated mainly in the anaerobic units of both traditional and reversed $A^{2} / O$ processes via volatilization and degradation (mainly for D4 and D5). Microbe catalysis hydrolysis was identified as one of the main degradation pathways for D4 and D5 in the anaerobic compartments.

\section{Acknowledgment}

This work was supported by the National Natural Science Foundation of China (No. 20837003, 20921063, 20890111) and the National Basic Research Program of China (2009CB421605).

\section{Appendix A. Supplementary data}

Supplementary data related to this article can be found at http://dx.doi.org/10.1016/j.watres.2012.10.046.

\section{R E F E R E N C E S}

Appels, L., Baeyens, J., Degrève, J., Dewil, R., 2008. Principles and potential of the anaerobic digestion of waste-activated sludge. Progress in Energy and Combustion Science 34, 755-781.

Boehmer, T., Gerhards, R., 2003. Decamethylcyclopentasiloxane (D5), a Compilation of Environmental Data. Degussa Goldschmidt AG, Essen. Centre Européen des Silicones, Brussels.

CES, 2005. Comments to the Draft Risk Assessment Dated 12 May 2005. Decamethylcyclopentasiloxane CAS No. 541-02-6 (D5).

CNKI, 2009. Available from: http://www.cnki.com.cn/Article/ CJFDTotal-YJGF200905013.htm (in Chinese).

Dewil, R., Appels, L., Baeyens, J., Buczynska, A., Vaeck, L.V., 2007. The analysis of volatile siloxanes in waste activated sludge. Talanta 74 (1), 14-19.

Dong, C., Zeng, Z., Yang, M., 2005. Determination of organochlorine pesticides and their derivations in water after HS-SPME using polymethylphenylvinylsiloxane-coated fiber by GC-ECD. Water Research 39, 4204-4210.

Dow Corning, 2005. Non-regulated Study: Method Development and Preliminary Assessment of the Hydrolysis Kinetics of Decamethylcyclopentasiloxane (D5) According to the Principles of OECD Guideline 111. Draft Report. Health and Environmental Sciences, Dow Corning Corporation, Auburn, MI.

EA, 2009a. Environmental Risk Assessment Report: Octamethylcyclotetrasiloxane. Final Draft Report. Environment Agency, Bristol.

EA, 2009b. Environmental Risk Assessment Report: Decamethylcyclopentasiloxane. Final Draft Report. Environment Agency, Bristol.

EA, 2009c. Environmental Risk Assessment Report: Dodecamethylcyclohexasiloxane. Final Draft Report. Environment Agency, Bristol.

EC, 2009. Available from: http://ecb.jrc.ec.europa.eu/ classification-labelling/.

EPA, 2002. Available from: http://www.epa.gov/oppt/iur/tools/ data/2002-vol.htm.

Flassbeck, D., Pfleiderer, B., Grumping, R., Hirner, A.V., 2001. Determination of low molecular weight silicones in plasma and blood of women after exposure to silicone gel-filled implants. Analytical Chemistry 73, 606-611.

Guedez, A.A., Püttmann, W., 2011. Occurrence and fate of TMDD in wastewater treatment plants in Germany. Water Research 45, 5313-5322.

He, B., Rhodes-Brower, S., Miller, M.R., 2003. Octamethylcyclotetrasiloxane exhibits estrogenic activity in mice via ER alpha. Toxicology and Applied Pharmacology 192, 254-261.

Huppmann, R., Lohoff, H.W., Schroeder, H.F., 1996. Cyclic siloxanes in the biological wastewater treatment process determination, quantification and possibilities of elimination. Fresenius' Journal of Analytical Chemistry 354, 66-71.

Kaj, L., Andersson, J., Palm, C.A., Remberger, M., BrorströmLunden, E., Cato, I., 2005. Results from the Swedish National Screening Programme 2004. Subreport 4: Siloxanes. Swedish Environmental Research Institute, Stockholm.

Kala, S.V., Lykissa, E.D., Lebovitz, R.M., 1997. Detection and characterization of poly (dimethylsiloxane)s in biological tissues by GC/AED and GC/MS. Analytical Chemistry 69, 1267-1272.

Kannan, Y.H.K., 2008. Survey of organosilicones compounds, including cyclic and linear siloxanes, in personal-care and household products. Archives of Environmental Contamination and Toxicology 55, 701-710.

Kazuyuki, O., Masaki, T., Tadao, M., Hiroshi, K., Nobuo, T., Akira, K., 2007. Behavior of siloxanes in a municipal sewage- 
treatment in plant. Journal of Japan Sewage Works Association 44, 125-138 (in Japanese).

Liebierman, M.W., Lykissa, E.D., Barrios, R., Qu, C.N., Kala, G., Kala, S.V., 1999. Cyclosiloxanes produce fatal liver and lung damage in mice. Environmental Health Perspectives 107, 161-165.

Luo, Y., Xu, L., Rysz, M., Wang, Y.Q., Zhang, H., Alvarez, P.J.J., 2011. Occurrence and transport of tetracycline, sulfonamide, quinolone, and macrolide antibiotics in the Haihe River Basin, China. Environmental Science and Technology 45, 1827-1833.

Mirsepasi, A., Honary, H.R., Mesdaghinia, A.R., Mahvi, A.H., Vahid, H., Karyab, H., 2006. Performance evaluation of full scale UASB reactor in treating stillage wastewater. Iranian Journal of Environmental Health Science and Engineering 3 (2), 79-84.

Negreira, N., Rodríguez, I., Rubí, E., Cela, R., 2010. Solid-phase microextraction followed by gas chromatography-mass spectrometry for the determination of ink photo-initiators in packed milk. Talanta 82, 296-303.

OEHHA, 2007. Toxicity Data Review:

Decamethylcyclopentasiloxane (D5). Available from: http:// www.arb.ca.gov/toxics/dryclean/oehhad5review.pdf.

Parker, W.J., Shi, J., Fendinger, N.J., Monteith, H.D., Chandra, G., 1999. Pilot plant study to assess the fate of two volatile methyl siloxane compounds during municipal wastewater treatment. Environmental Toxicology and Chemistry 18, 172-181.

Pazarro, C., Pérez-del-Notario, N., Conzález-Sáiz, J.M., 2010. Optimisation of a simple and reliable method based on headspace solid-phase microextraction for the determination of volatile phenols in beer. Journal of Chromatography A 1217, 6013-6021.

Sanchez-Brunete, C., Miguel, E., Albero, B., Tadeo, A.J., 2010. Determination of cyclic and linear siloxanes in soil samples by ultrasonic-assisted extraction and gas chromatography-mass spectrometry. Journal of Chromatography A 1217 (45), 7024-7030.

Silicones Environmental, Health and Safety Council of North America (SEHSC), 2011. Available from: http://www.sehsc. com/d5.asp.

Song, M., Chu, S.G., Letcher, R.J., Seth, R., 2006. Fate, partitioning, and mass loading of polybrominated diphenyl ethers (PBDEs) during the treatment processing of municipal sewage. Environmental Science and Technology 40, 6241-6246.

Sparham, C., Egmond, R.V., O'Connor, S., Hastie, C., Whelan, M., Kanda, R., Franklin, O., 2008. Determination of decamethycyclopentasiloxane in river water and final effluent by headspace gas chromatography/mass spectrometry. Journal of Chromatography A 1212, 124-129.

Stiles, R., Yang, I., Lippincott, R.L., Murphy, E., Buckley, B., 2008. Measurement of drinking water contaminants by solid phase microextraction initially quantified in source water samples by the USGS. Environmental Science and Technology 42, 2976-2981.

Varaprath, S., Slayers, K.L., Plotzke, K.P., Nanavati, S., 1999. Identification of metabolites of octamethylcyclotetrasiloxane (D4) in rat urine. Drug Metabolism and Disposition 27 (11), 1267-1273.

Warner, N.A., Evenset, A., Christensen, G., Gabrielsen, G.W., Borgå, K., Leknes, H., 2010. Volatile siloxanes in the European arctic: assessment of sources and spatial distribution. Environmental Science and Technology 44 (19), 7705-7710.

Whelan, M.J., Sanders, D., van Egmond, R., 2009. Effect of Aldrich humic acid on water-atmosphere transfer of decamethylcyclopentasiloxane. Chemosphere 74 (8), 1111-1116.

Zhou, Q., Tan, J., Zhang, A.X., Zeng, X.H., 2009. Progress on silicon industry in foreign countries in 2008. Silicone Material 23 (5), 315-323 (in Chinese). 